\title{
Enfermidades prevalentes, causas de mortalidade e gastos com tratamento de bezerros leiteiros na região do Médio Paraíba - Rio de Janeiro e Minas Gerais
}

\section{Infirmities prevalents, mortality causes and expenses with dairy calves treatment in the area of Medium Paraíba - Rio de Janeiro and Minas Gerais}

\author{
Rita de Cássia Campbell Machado Botteon, ${ }^{\star}$ Paulo de Tarso Landgraf Botteon, ${ }^{\star *}$ Juracy de Castro Santos Júnior, ${ }^{\star \star *}$

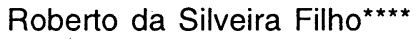

\begin{abstract}
Resumo
As pressões de mercado exigem uma eficiência cada vez maior no uso de fatores de produção e controle dos custos da atividade leiteira. $O$ incremento na produtividade se dá através de práticas que reduzam as perdas e os gastos nas diferentes fases da produção. O presente trabalho foi desenvolvido visando identificar as principais enfermidades, causas de mortalidade e gastos com tratamento em bezerros leiteiros de 1 a 90 dias de idade. O levantamento foi efetuado de agosto de 1998 a julho de 1999, em 20 Unidades de Produção de Leite tipo C, localizadas entre Valença, Rio das Flores (RJ) e Rio Preto (MG). Foram examinados 1974 bezerros; 35,8\% (706) apresentaram evidência clínica de diarréia. Destes, 55,2\% apresentaram fezes de consistência mole ou líquida. Outras enfermidades identificadas ao exame clínico foram: onfalite $(4,3 \%)$, lesões de pele de etiologia não pesquisada $(4,1 \%)$, processos inflamatórios do aparelho respiratório (3\%), miíase na cicatriz umbilical $(0,96 \%)$, poliartrite $(0,65 \%)$ e hérnia umbilical $(0,56 \%)$. Foram identificados 85 bezerros com sinais clínicos de Tristeza Parasitária $(4,3 \%)$. No mesmo período foram informados tratamentos para processos diarréicos, afecções pulmonares e "Tristeza" em 157 (8\%) e a morte de 76 animais por diarréia. Através de entrevista pessoal, obteve-se a opinião de criadores sobre as doenças mais freqüentes, causas de mortalidade e gastos com tratamento. A maioria atribuiu à "Tristeza" o maior número de mortes e gastos com medicamentos. Diarréia foi considerada a enfermidade de maior freqüência. Verminose pareceu ser preocupante somente quando ocorre um surto de "diarréia de sangue". O custo aproximado do tratamento de um caso de diarréia foi calculado considerando-se o número de animais tratados, a média de preços dos produtos, dosagens e número de aplicações informadas pelos criadores. A estimativa de gasto por animal foi equivalente a $R \$ 2,77$ (dois reais e setenta $e$ sete centavos), o mesmo que 9,2 litros de leite, considerando $R \$ 0,30$ (trinta centavos) o preço médio por litro de leite pago ao produtor no período.
\end{abstract}

Palavras-chave: enfermidades, bovinos, bezerros, mortalidade

\begin{abstract}
Nowadays, productivity and control factors at dairy's costs are under market pressure for yielding increased efficiency, so it is necessary to link strategies for reducing losses and lowering the costs at different steps of production. The present work was developed in order to identify the principal diseases, causes of mortality and expenses of treatment with dairy calves from 1 to 90 days old. To reach these numbers, an inquiry was performed from August 1998 to July 1999 at 20 Dairy's Unities Type C at the cities of Valença (RJ), Rio das Flores (RJ) and Rio Preto (MG). 1974 calves were examined, 35,8\% (706) presented clinical evidence of diarrhea. Of these, $55,2 \%$ presented soft or liquid feces. Other diseases were identified in clinical examination: onphalitis $(4,3 \%)$, skin's injuries $(4,1 \%)$, respiratory inflammation $(3 \%)$, miiasis in umbilical cicatrix $(0,96 \%)$, poliarthritis $(0,65 \%)$ and umbilical hernia $(0,56 \%) .85$ calves with signs of tick born disease were identified $(4,3 \%)$. In same period, treatment for diarrhea, pulmonary processes and tick fever were informed in 157 calves (8\%) and 76 died for diarrhea cause. Producers were interviwed to acquire their opinion about the most frequent diseases, mortality causes and expenses with treatment. Most attributed to the tick born disease the largest number of deaths and expenses with medication. Diarrhea was considered the most frequent disease, but worms only worried when it happens an outbreak of "diarrhea of blood". The approximate cost of the treatment of a case of diarrhea was calculated being considered the number of treated animals, the average of prices of the

\footnotetext{
* Departamento de Medicina e Cirurgia Veterinária (DMCV) - Instituto de Veterinária (IV) - Universidade Federal Rural do Rio de Janeiro (UFRRJ) - BR 465 Km 07, Seropédica, RJ, CEP: 23851-970 - E-mail: rbotteon @ ufrrj.br

** DMCV / IV / UFRRJ - E-mail:pbotteon@ufrrj.br



**** Médico-veterinário autônomo.
} 
products, dosages and number of informed applications for the creators. The expense estimate for animal was equivalent to $\mathrm{R} \$$ 2,77 (two real and seventy seven cents), the same as 9,2 liters of milk, considering $R \$ 0,30$ (thirty cents) the medium price for liter of milk pays to the producer in the period.

Keywords: diseases, bovine, calves, mortality.

\section{Introdução}

Nos últimos anos a pecuária leiteira nacional empreendeu grandes avanços. Estatísticas apontam para o aumento do número de rebanhos especializados. Contudo, dados da Associação Brasileira dos Produtores de Leite revelam que a maior parte do leite produzido no país é proveniente de pequenos produtores que operam com baixa produtividade e têm participação decrescente na oferta global de leite. Atualmente, as pressões de mercado exigem uma eficiência cada vez maior no uso de fatores de produção e controle dos custos da atividade leiteira. A garantia de resultados tem-se traduzido pelo incremento na produtividade por animal e por área, através de práticas de manejo que reduzam as perdas e os gastos, nas diferentes fases da produção. A fase de cria dos bezerros recebe pouca atenção por parte do produtor rural, sobretudo porque além de não gerar lucros imediatos, em geral, representa despesas. Há de se considerar que sistemas de criação inadequados causam prejuízos pela perda de animais e gastos com medicamentos. Em termos mundiais os processos diarréicos têm sido apontados como a mais importante causa de mortalidade em bezerros. Estudos realizados em Minas Gerais, São Paulo e Rio Grande do Sul (Figueiredo, 1979; Oliveira Filho, 1973; Scheneider, 1981; Langenegger et al., 1974; Leite e Lima, 1982; Prado, 1991; Botteon et al., 2002) apontam a diarréia dos bezerros como uma das mais importantes causas de mortalidade em animais jovens e prejuizos à pecuária leiteira nacional. Apesar das estimativas não há dados oficiais sobre os prejuízos acarretados pela diarréia em diferentes formas de criação. Acredita-se que as perdas sejam elevadas, especialmente considerando-se o grau de aperfeiçoamento e o manejo dos rebanhos no Brasil. Os prejuizos incluem as perdas pela morte, 0 custo da medicação e mão-de-obra envolvidas no tratamento, além da produtividade reduzida dos animais afetados. $O$ presente trabalho teve por objetivo identificar as principais enfermidades prevalecentes e a importância da diarréia como causa de mortalidade e gastos com tratamento em bezerros leiteiros lactentes, categoria bastante negligenciada pelo pequeno produtor, em virtude dos prejuízos freqüentemente impostos por mortalidade, gastos com mão-de-obra e tratamento de enfermidades.

\section{Material e métodos}

De uma relação de Unidades de Produção de Leite tipo C, localizadas entre os municípios de Valença, Rio das Flores (RJ) e Rio Preto (MG), foram selecionadas 32 propriedades, nas quais foi aplicado um questionário para avaliação das condições higiênico-sanitárias através de entrevista pessoal, em agosto de 1998. A área foi escolhida pelo grande número de propriedades leiteiras e facilidade de acesso através dos Médicos-veterinários que atuam na região. Informações referentes ao tipo de manejo, práticas de higiene, controle parasitário, tamanho da propriedade, número de ani- mais, rnão-de-obra utilizada, forma de ordenha, higiene ambiental e da ordenha, tipo de bezerreiro e forma de criação dos bezerros entre outras, foram obtidas através de entrevista com proprietários, administradores ou encarregados de currais. Neste período estabeleceu-se como propósito identificar, agrupar e caracterizar as formas de produção e organização das propriedades, buscando construir um perfil, mediante atributos técnicos e sanitários. Após a primeira visita, o grupo de propriedades foi reduzido para 20 , concorrendo para este efeito a permissão para vistas mensais, as condições de acesso, proximidade entre os grupos e facilidade de obtenção de informações referentes à idade e identificação dos bezerros. O levantamento das enfermidades prevalecentes foi efetuado de agosto de 1998 a julho de 1999, periodo em que foram realizadas 10 visitas a cada propriedade, em intervalos aproximados de um mês. A cada visita foram examinados todos os bezerros não desmamados de 1 a 90 dias de nascidos, que se encontravam no bezerreiro no momento das visitas. Após uma observação geral, foram contados o número total de bezerros, animais com sinais ou evidência clínica de diarréia, caracterizada por nádegas, jarrete ou cauda sujos de fezes, e examinados individualmente todos os animais com até 90 dias de idade. Ocasionalmente, se não foi informada a existência de animais com menos de 90 dias, a informação foi anotada e nenhum animal foi examinado. $O$ exame clínico individual foi conduzido no sentido de identificar sinais ou sintomas clínicos de diarréia ou moléstias intercorrentes, iniciando-se pela inspeção das condições gerais do paciente, avaliação do estado higiênico e nutricional, características da pele e pelagem, inspeção dos linfonodos periféricos e umbigo, observação das mucosas (oral e ocular), presença e características das secreções ocular e nasal, presença de tosse ou ruídos respiratórios. Em seguida procedeu-se ao exame do turgor cutâneo e ocular, mensuração do tempo de preenchimento capilar (TPC), aferição da temperatura retal e das extremidades, obedecendo-se a seqüência do protocolo estabelecido. Durante o exame clínico, foram observadas as características das fezes relativas ao aspecto, coloração, odor, quantidade, freqüência da defecação, presença de substâncias anormais, sinais de dor à defecação etc. Através de inquérito pessoal, procurou-se realizar um levantamento dos produtos utilizados para o tratamento dos casos de diarréia ocorridos em cada propriedade no tempo decorrido entre as visitas, e os resultados obtidos, anotandose o número de animais doentes, tratados e o índice de recuperação informados. Como tratamento foram considerados a hidratação oral ou parenteral, antibioticoterapia, além da utilização de produtos alternativos ou a associação desses.

\section{Resultados e discussão}

Foram examinados 1974 bezerros lactentes de 1 a 90 dias de idade e $35,8 \%$ (706) apresentaram evidência clínica de diarréia, caracterizada por nádegas, cauda ou jarrete sujos de fezes. Dos bezerros com evidência de diarréia, $390(55,2 \%)$ 
apresentaram fezes de consistência variando de mole a líquida, características de diarréia (Hall et al., 1992; Smith, 1993). Outras enfermidades identificadas entre os 1974 bezerros examinados (Tabela 1 ) foram: onfalite $(4,3 \%)$, lesões de pele de etiologia não pesquisada $(4,1 \%)$, processos inflamatórios do aparelho respiratório (3\%), miíase na cicatriz umbilical $(0,96 \%)$, poliartrite $(0,65 \%)$ e hérnia umbilical $(0,56 \%)$. Não foram realizados esfregaços de sangue periférico para pesquisa de hemoparasitos, porém ao exame clínico foram identificados 85 bezerros com sinais clínicos sugestivos de Tristeza Parasitária Bovina $(4,3 \%)$. No mesmo período foram informados tratamentos para processos diarréicos, pulmonares e "Tristeza" em 157 (8\%) e a morte de 76 animais por diarréia.

Através de entrevista pessoal, procurou-se obter a opinião de criadores e encarregados sobre as principais doenças em termos de ocorrência, causa de mortalidade e responsáveis por maiores gastos com tratamento. A maioria atribuiu à "Tristeza" o maior número de mortes de bezerros e a esta mesma enfermidade os maiores gastos com medicamentos (Tabela 2). A freqüência de visitas mensais nos permitiu constatar que, como "Tristeza", são consideradas diferentes patologias que determinam especificamente febre, apatia e lacrimejamento. Todas as enfermidades que resultaram neste quadro clínico foram tratadas de forma semelhante e consideradas pelos proprietários ou encarregados como "Tristeza". Diarréia foi considerada como a enfermidade de maior freqüência, mas segundo informações, não determinam muitos prejuízos porque muitos animais se recuperam sem tratamento ou mediante uma ou duas aplicações de antibiótico. Verminose pareceu ser preocupante somente quando ocorre um surto de "diarréia de sangue", a qual é atribuída à verminose. Esses casos geralmente são tratados com antihemorrágicos e/ou sulfonamidas e vermífugo.

Tabela 1: Enfermidades identificadas ao exame clínico de bezerros lactentes, em unidades de produção de leite, no Vale do Rio Preto, de agosto de 1998 a julho de 1999

$\begin{array}{ccccccc}\text { Examinados } & \begin{array}{c}\text { Sinais de } \\ \text { Diarréia }\end{array} & \text { Diarréia } & \text { AR } & \text { Pele } & \text { Onfalite } & \text { Mortes } \\ 1974 & 706 & 390 & 61 & 82 & 85 & 76\end{array}$

*AR = manifestações de processo inflamatório do aparelho respiratório; Pele = Lesões de pele de etiologia não pesquisada; Onfalite = onfaloflebite.

Tabela 2: Principais doenças em relação à mortalidade, gastos com medicamentos e freqüência, em unidades de produção de leite, no Vale do Rio Preto, segundo a opinião de proprietários ou encarregados entrevistados

\begin{tabular}{|c|c|c|c|c|}
\hline & Diarréia & Verminose & "Tristeza" & Outras \\
\hline $\begin{array}{l}\text { Mortalidade e Gastos } \\
\text { Maior Freqüência }\end{array}$ & $\begin{array}{l}35 \% \\
75 \%\end{array}$ & $\begin{array}{l}10 \% \\
10 \%\end{array}$ & $\begin{array}{l}40 \% \\
15 \%\end{array}$ & $15 \%$ \\
\hline
\end{tabular}

Informações semelhantes quanto às principais enfermidades que acometem os bovinos leiteiros jovens, foram registradas em entrevistas a criadores em outros municípios de Minas Gerais (Leite e Lima, 1982; Viana et al., 1987; Moreira, 1988; Prado, 1991). Prado (1991) relatou diarréia e "Tristeza" como responsáveis por $62 \%$ das mortes de bezerros. Leite e Lima (1982), em estudo sobre os fatores sanitários que influ- enciam a criação de bezerros, utilizando-se de inquérito de opinião aplicado aos criadores da região de Sete Lagoas MG, relataram mortalidade de $17,6 \%$ dos bezerros e "curso" ou diarréia como a doença mais freqüente, segundo a opinião de $98 \%$ dos entrevistados. Plasmose foi considerada a segunda enfermidade mais freqüente por $56,6 \%$ na região. estudada por estes autores.

Ainda através de inquérito de opinião aplicado aos proprietários, administradores ou encarregados de currais, procurouse obter informações relativas aos gastos mensais com medicamentos utilizados para o tratamento dos processos diarréicos que acometem os bezerros do nascimento ao desmame e o custo aproximado de um caso de diarréia na propriedade. A cada visita foram anotados o número de animais que adoeceram, número de animais tratados, produtos e doses utilizadas. Cinco encarregados (25\%) informaram que os gastos e o custo do tratamento são elevados em virtude do número de casos ocorridos. Outros três (15\%) informaram que os gastos são pequenos, e esses, em geral, tiveram poucos casos de diarréia. Dez entrevistados (50\%) informaram não fazer idéia do gasto mensal ou do custo do tratamento de animais com diarréia em seus rebanhos, mas informaram acreditar que o gasto é elevado. Somente dois entrevistados $(10 \%)$ souberam informar o gasto mensal, mas informaram que além do gasto com medicamentos, a diarréia causa prejuízos indiretos que não sabem calcular. Os gastos informados por estes criadores para o tratamento de diarréia foram respectivamente 5,80 a 15 reais. Os proprietários que não souberam informar o custo do tratamento, de uma maneira geral utilizam produtos aleatoriamente e não em todos animais e não souberam informar com exatidão quantos animais foram acometidos ou tratados nem a eficiência do tratamento instituido.

Dezoito produtos com nomes comerciais diferentes, ainda que alguns com o mesmo princípio ativo, foram utilizados para 0 tratamento dos animais enfermos. As bases medicamentosas dos produtos mais citadas foram: cloridrato de oxitetraciclina, cloranfenicol, associação de trimetoprim + sulfadiazina e sulfonamidas. Um produto constituído pela associação de benzamidina e oxitetraciclina indicado para o tratamento do complexo Tristeza Parasitária foi citado em sete ocasiões. Dois tratadores referiram-se ao acréscimo na oferta de leite como medida curativa dos processos diarréicos ocorridos na propriedade em duas ocasiões distintas. Um proprietário justifica que o aumento na oferta de leite fortalece o animal e acelera a recuperação. Restrição de leite ou o jejum por cerca de 24 horas foram citados por dois encarregados como eficiente e único tratamento instituído. Aplicação de produto antiparasitário foi utilizado em duas ocasiões quando animais mais velhos adoeceram. Soro caseiro, em quantidade aproximada de 1 litro por animal em duas ou três aplicações diárias, chá de goiabeira e diluição de cerca de $100 \mathrm{~g}$ de cinza de fogão de lenha em meio litro de água fornecido por uma ou duas vezes foram os tratamentos alternativos citados.

O custo aproximado do tratamento foi calculado considerando-se a média de preços dos produtos, dosagens e número de aplicações informadas pelos criadores, considerando-se o número de animais tratados. A estimativa de gasto com medicamentos no tratamento de um animal foi equivalente a $R \$ 2,77$ (dois reais e setenta e sete centavos), o mesmo que 9,2 litros de leite, considerando $\mathrm{R} \$ 0,30$ (trinta centavos) 0 
preço médio por litro de leite pago ao produtor no período. A média dos preços dos medicamentos utilizados na região estudada foi de $R \$ 2,36$ (dois reais e trinta e seis centavos). Considerando-se os gastos citados pelos criadores (5,8 e 15 reais), ambos teriam tratado 2,1 e 5,4 animais, o que equivale a 19,3 e 50 litros de leite para o tratamento destes animais. Os preços utilizados para cálculo referem-se à média dos preços praticados em agosto de $1999 \mathrm{em}$ duas lojas do município de Seropédica, próximas à Universidade Rural.

\section{Referências}

BOTTEON, R.C.C.M., BOTTEON, P.T.L., LÓSS, Z.G. Aspectos sanitários da pecuária leiteira na região do Médio Paraíba - Rio de Janeiro e Minas Gerais. Revista Brasileira de Ciência Veterinária, v. 8, n. 3, p.141-143, 2001.

FIGUEIREDO, M. C. P. Alguns aspectos da situação sanitária bovina no município de Uberaba, Minas Gerais. 1979.172 p. Tese (Mestrado)Escola de Veterinária - Universidade Federal de Minas Gerais.

HALL,G. A; JONES, P. W.; MORGAN, J. H. Calf diarrhea. In: ANDREW, BLOWEY, BOYD \& EDDY. Bovine Medicine - Diseases and Husbandry of Cattle. Oxford: Editora Blackwell Scientific Publications, 1992, p.154180.

LANGENEGGER, J.; COELHO, N. M.; MENKE, L. G. Manejo deficiente, o maior problema da criação de bezerros. Biol. Campo. Rio de Janeiro. v. 262 , n. 11, p. 60-64, 1974.

LEITE, R. C.; LIMA, J. D. Fatores sanitários que influenciam na criação de bezerros. Arquivos da Escola de Veterinária - UFMG, Belo Horizonte, v. 34, n. 3, p. 485-492, 1982.

LUCCI, C. Bovinos leiteiros jovens: nutrição, manejo e doenças. São Paulo: Editora Nobel, 1989.

\section{Conclusões}

Diarréia se constitui numa importante enfermidade de bezerros e os prejuízos são, sobretudo, decorrentes da utilização de medidas inadequadas de tratamento e controle. Diversos aspectos relacionados às drogas utilizadas no tratamento da diarréia deveriam ser mais bem avaliados antes de serem amplamente difundidos entre os criadores, na maioria leigos e sem nenhum tipo de orientação especializada.

MOREIRA, F. X. Condições sanitárias e estrutura de produção na bovinocultura dos núcleos de João Pinheiro e Rio Verde no Estado de Minas Gerais. 1988. 92 p. Tese (Mestrado)-Escola de Veterinária da Universidade Federal de Minas Gerais.

OLIVEIRA FILHO, E. B. Apreciação preliminar da situação da pecuária leiteira em cinco localidades dos Estados de São Paulo e Minas Gerais. Arquivos Escola de Veterinária - UFMG. Belo Horizonte, v. 25, n. 2, p. 157-168, 1973.

SCHNEIDER, I. A. Integração do agricultor no processo de produção e distribuição de novos conhecimentos. Implicações teóricas, práticas e metodológicas. Veterinária Economia Rural. Brasília. v. 19, n. 2, p. 316-325, 1981.

SMITH, B. P. Tratado de medicina interna de grandes animais. São Paulo: Editora Manole, 1580 p. 1993.

PRADO, E. Características sócio-econômicas e sanitárias da pecuária bovina do municipio de Divinópclis, Minas Gerais. Tese (Mestrado)Escola de Veterinária da Universidade Federal de Minas Gerais. 1991.

VIANA, F. C., CRUZ, F.E.R., LAENDER, F.C. Diagnóstico da situação de produção bovina de leite do Município de Sete Lagoas - MG. Arquivo Brasileiro de Medicina Veterinária Zootecnia, v. 39, n. 5, p. 669-717, 1987. 